\title{
GREVE: UMA REVISÃO BIBLIOGRÁFICA NOS CONTEXTOS JURÍDICO E SOCIAL
}

\section{REVISÃO BIBLIOMÉTRICA}

FRANÇA, Josimar Fernandes De ${ }^{1}$

FRANÇA, Josimar Fernandes De. Greve: uma revisão bibliográfica nos contextos jurídico e social. Revista Científica Multidisciplinar Núcleo do Conhecimento. Ano 04, Ed. 05, Vol. 06, pp. 243-255. Maio de 2019. ISSN: 2448-0959

\section{RESUMO}

Num mundo de rápidas e constantes transformações, as relações de trabalho se modernizam e se tornam mais maduras, porém não menos tensas. O conflito de interesses entre patrões e empregados se manifesta num aumento sensível no número de greves em nosso país nos últimos anos. A greve é um direito garantido pela Constituição, cabendo ao trabalhador buscar esse direito e lutar por ele, bem como definir seus interesses claramente com o movimento grevista. Ao longo da história do país muitas foram as conquistas com relação ao direito de greve, consolidando-se ainda na década de 1980. Mais do que um estatuto jurídico, a greve possui caráter social e vem se consolidando, ao longo da história, como força para a materialização de melhores condições de trabalho. O presente artigo busca, a partir da revisão bibliográfica sobre o tema, discorrer sobre a greve em seus pontos de vista jurídico e social, demonstrando suas características e importância no cenário das lutas trabalhistas contemporâneas.

Palavras-Chave: Greve, Direito do Trabalho, Direito Coletivo do Trabalho.

\footnotetext{
${ }^{1}$ Formado em Administração de pela UPIS - Consultor e Administrador de Empresas, Especialista em Direito processual Trabalhista pela UNINTER e Mestrando Gestão e Produção no Agronegócios na UNIDERP.
} 


\section{INTRODUÇÃO}

A despeito da ampla automação presente em todos os segmentos da economia, o ser humano continua sendo o principal capital das organizações. Tratada como commoditie no cenário atual, a qualidade técnica de um produto ou serviço só pode ser validada pelo mercado consumidor quando acompanhada de bom atendimento, inovação, políticas de relacionamento e outros diferenciais estritamente relacionados ao Ser Humano.

A relação histórica do capital x trabalho descrita por Marx (1996) vem sendo substituída gradualmente por relações mais fluidas que envolvem novos regimes de trabalho, novas políticas de horário, novas maneiras de atrair e reter talentos. Porém todo esse esforço, aparentemente, não torna a relação entre empresários e trabalhadores menos tensa. Mão de obra qualificada, amplo acesso à informação a partir do advento da internet, acesso facilitado ao estudo formal são apenas alguns dos fatores que modificam o perfil da mão-de-obra brasileira, cada vez mais exigente e conhecedora de seus direitos.

Dados do DIEESE (2013) reafirmam que, a despeito da nova realidade das relações trabalhistas, a tensão entre patrões e empregados continua presente, tornando a relevância do estudo da greve bastante atual. O Brasil teve em 2012 o maior número de greves dos últimos 16 anos, conforme apresentado no Gráfico 1, abaixo: 
Gráfico 1: Número de greves no Brasil

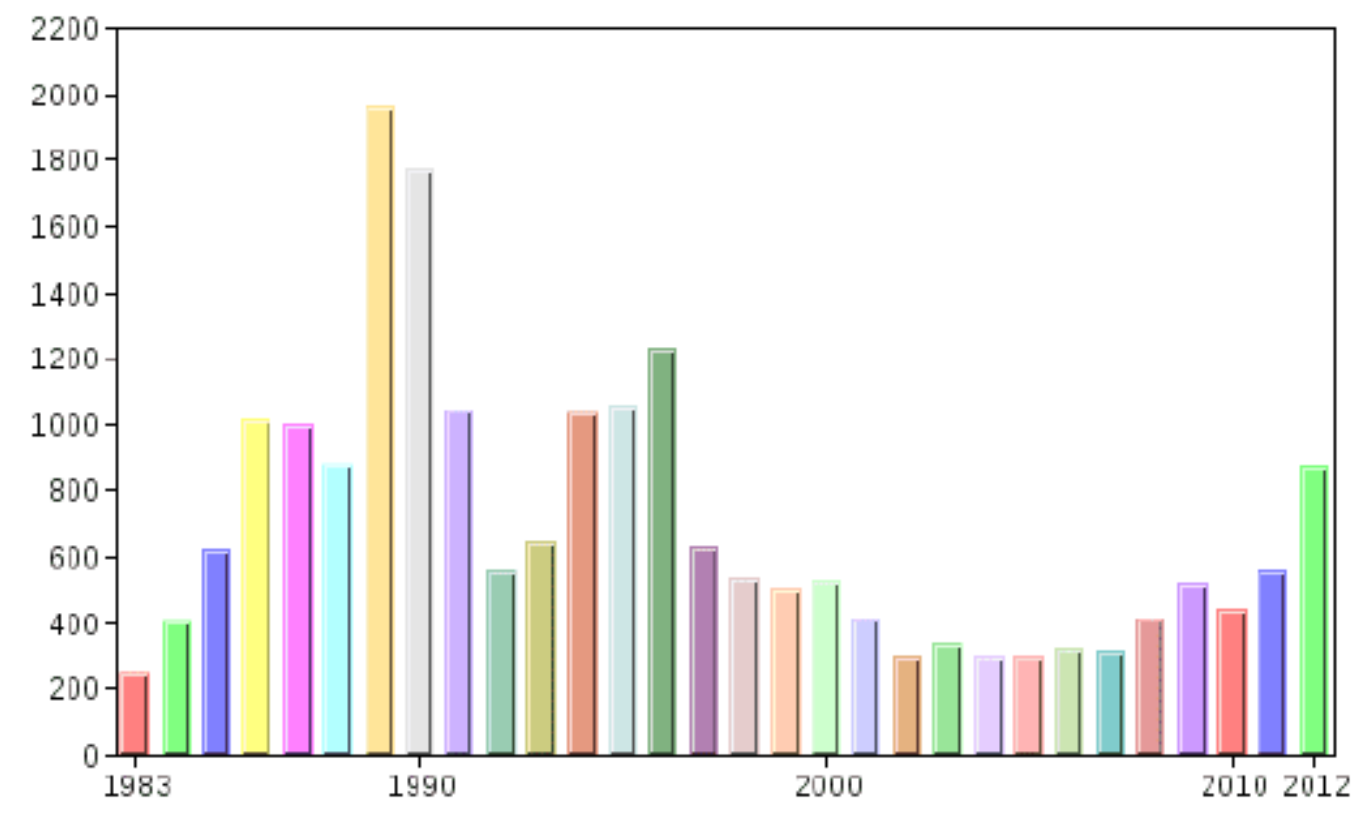

Fonte: DIEESE (2013)

Tais paralisações tiveram como motivação fatores diversos, com destaque para as demandas por reajuste salarial e implantação ou reajuste de benefícios (DIEESE, 2013).

Diante desse cenário mutante e dinâmico do mercado de trabalho nacional, o presente artigo é uma forma de demonstrar caráter qualitativo, sobre o tema da greve, tanto do ponto de vista jurídico como quanto movimento social, salientando sua importância como instrumento de conquistas trabalhistas na relação patrão $x$ empregado.

A presente pesquisa se desenvolve a partir de uma abordagem qualitativa, ou seja, o que se pretende descrever e interpretar - o fenômeno da greve - tem atenção aos detalhes, buscando construir e consolidar as teorias já existentes (MARTINS; TEÓPHILO, 2009, p.141).

Quanto aos meios, o artigo se utiliza da pesquisa bibliográfica e documental (MARTINS; TEÓPHILO, 2009) junto a legislação aplicada à greve, bem como artigos 
científicos recentes tratando do tema, com o objetivo de traçar um panorama teórico geral sobre a mesma temática

\section{O FENÔMENO DA GREVE E SUAS IMPLICAÇÕES}

Essa pesquisa se inicia com a discussão dos aspectos conceituais que envolvem o fenômeno da greve e suas implicações, tentando com isso traçar um cenário legal / regulatório a respeito do tema, para então passar a discorrer sobre a greve enquanto ato social, configurando-se como mecanismo de luta de classes.

\section{GREVE: CONCEITUAÇÃO}

Como temática principal desse artigo, é fundamental que se apresente, de início, as origens e conceituação da greve. O termo greve advém de uma localidade - a praça de Grève, em Paris. Nessa praça, durante a I Revolução Industrial, trabalhadores se reuniam para conversar, reivindicar, manifestar-se contra os patrões e proceder às suas paralizações. Com o tempo, o ato de estar na praça de Grève acabou por significar a paralização, ou "estar em greve" (GILLON, 1960, p. 493).

Estudado em diversos ramos das ciências sociais, principalmente na sociologia, o fenômeno da greve se reflete até mesmo na infraestrutura social. Contudo, tal conceito varia de acordo com a legislação local, sendo seu entendimento associado ao direito ou liberdade, no caso de a admitir, ou ao delito, na hipótese de a proibir.

Para Nascimento (2007, p. 1170) "a greve é um direito individual de exercício coletivo, manifestamente como autodefesa". Em outra frente, Boldt (1961), coloca a greve como uma interrupção coletiva e combinada do trabalho por certo número de trabalhadores da mesma profissão ou empresa, tendo um objetivo de luta, a fim de que os seus interesses sejam atingidos.

O entendimento de Hauriou (1961) sobre o tema é de que a greve implica em abstenção do trabalho de forma organizada, impetrada por funcionários assalariados de uma ou mais empresas no sentido de pressionar empregadores ou outros atores a 
eles associados na busca de melhores condições de trabalho. Tal entendimento é corroborado também por Süssekind (1999).

Do ponto de vista legal, a greve é considerada no art. $2^{\circ}$ da Lei ํo $7.783 / 89$ como "suspensão coletiva, temporária e pacífica, total ou parcial, de prestação pessoal de serviços a empregador". Ademais, o Art. $7^{\circ}$, XXXIV da Lei Magna, diz que o exercício do direito de greve é assegurado apenas ao trabalhador subordinado, não podendo ser exercido pelo trabalhador autônomo, mas poderá ser exercido pelo trabalhador avulso, pois este tem igualdade de direitos em relação ao trabalhador com vínculo permanente.

Em todos os conceitos é possível extrair que a greve é uma forma de protesto perante ao empregador pelo trabalhador, a fim de forçar o atendimento de suas reinvindicações, sejam elas associadas a salários, benefícios ou outra condição de trabalho.

A paralização do trabalho poderá ser de maneira total ou parcial, podendo abranger toda a empresa ou apenas alguns setores ou seções desta. De acordo com a Constituição Federal (1988) a greve é, portanto, considerada como um direito social dos trabalhadores.

\section{NATUREZA JURÍDICA DA GREVE}

Para se entender a natureza jurídica da greve no Brasil é necessário, de princípio, enquadrá-la como liberdade decorrente do exercício de uma determinação lícita, uma vez que, de acordo com a Constituição da República (1988, Art. 9º), a greve é um direito fundamental reconhecido no Brasil.

A greve, enquanto direito protestativo, não admite oposição. A parte contrária, ou seja, o empresariado, terá de se sujeitar ao exercício desse direito. Também é um direito coletivo, pois é no grupo que o exercicio de direito de greve alcançará seu objetivo final. De fato, a natureza jurídica da greve dá conta da greve como "direito fundamental 
de caráter coletivo, resultante da autonomia privada coletiva inerente às sociedades democráticas" (DELGADO, 2009, p.1315)

Sendo a greve dispositivo sem força nem amparo jurídico, ou se for realizada por um único indivíduo, desvirtua-se de sua natureza jurídica, cabendo justa causa para a rescisão do contrato de trabalho. Quanto ao contrato de trabalho, ocorrem alguns efeitos durante a greve: como suspenção ou interrupção do mesmo. No caso da suspenção, não ocorre o pagamento de salários e nem a contagem do tempo de serviço (Lei no $7.783 / 89$ ).

Como o direito de greve é um direito social fundamental conforme rege a Constituição da República, é assegurando tal direito a todos os trabalhadores, não o proibindo nas atividades essenciais. $O \S 1^{\circ}$ do art. $9^{\circ}$ da Constituição dispõe sobre a não proibição da greve em atividades essenciais, apenas determina que a lei irá definir os serviços ou atividades essenciais, o que foi feito pelo artigo 10 da Lei $\mathrm{n}^{0} 7.783 / 89$.

Esses serviços são aqueles inadiáveis que, não atendidos, colocam a população em perigo eminente a sobrevivência, saúde ou a segurança da população.

Consideram-se serviços ou atividades essenciais, portanto:

(a) tratamento e abastecimento de água; produção e distribuição de energia elétrica, gás e combustíveis; (b) assistência médica e hospitalar; (c) distribuição e comercialização de medicamentos e alimentos; (d) funerários; (e) transporte coletivo; (f) captação e tratamento de esgoto e lixo; (g) telecomunicações; (h) guarda, uso e controle de substancias radioativas, equipamentos e materiais nucleares; (i) controle de tráfego aéreo; (j) compensação bancária. São taxativas tais situações, e meramente exemplificativas. Outras atividades ou serviços não serão considerados como essenciais, como escolas ou correio. (Lei $\mathrm{n}^{\circ}$ 7.783/89, Art. 10) 
Assim, conforme exposto, o direito de greve é amplo, contemplando todo tipo de segmento de trabalho, incluindo-se aqueles contemplados por lei como serviços essenciais, desde que respeitadas suas características peculiares.

\section{DIREITOS DOS GREVISTAS E EMPREGADORES}

Embora indiscutível a relevância dos movimentos grevistas sob a égide das manifestações coletivas da liberdade humana, do ponto de vista democrático é salutar sua regulação em termos do Direito. Uma vez regulamentada juridicamente, a greve torna-se mais viável e eficaz, não representando necessariamente um instrumento de inibição de tais movimentos (DELGADO, 2009).

Avaliando-se historicamente os principais dispositivos legais brasileiros a respeito do tema da greve, tem-se como precursor o Código Penal (Decreto n. 847, 11 de outubro de 1890), que proibia a greve, enquadrando-a como ilícito penal. Já a Constituição Federal de 1937 entendia como livre a associação profissional ou sindical (Art. 138), prevendo a greve e o lockout como recursos antissociais, nocivos ao trabalho, ao capital e incompatíveis com os superiores interesses da produção nacional (Art. 139). Em 1940 o Código Penal passa a enquadrar a greve como crime, no caso de paralisação de trabalho seguida de violência ou perturbação da ordem ou interesse público (Arts. 200 e 201). Na mesma década, em 1943, a Consolidação das Leis do Trabalho (Decreto-lei oㅜ 5.452, de 01/05/43) trata, em sua Seção I, Capítulo VII, do lockout e da greve como manifestações proibidas, podendo gerar penalidades como suspensão ou dispensa do emprego, além de perda ou suspensão do direito de serem eleitos para o cargo de representação profissional (Art. 723).

Algum avanço foi conseguido através da Constituição Federal, de 18 de setembro de 1946, que admitiu o direito de greve e foi regulamentada pelo Decreto-lei n. 9.070/46, considerado como primeira lei ordinária sobre greve, que a permitia nas atividades acessórias. Em contraponto, a Lei ํo 4.330, de 1ํ de junho de 1964, cuja regulamentação do direito de greve previsto no art. 158 da CF/46 era tamanho complexa, ficou conhecida como "Lei anti-greve". 
A Constituição Federal de 1967 assegurou aos trabalhadores o direito de greve (art. 158, XXI), salvo nos serviços públicos e atividades essenciais (art. 157, § $7^{\circ}$ ), complementada pela Emenda Constitucional № 1, de 17/10/69, tratando da mesma permissão. Já a Lei no 6.128/78, proibiu a greve nas sociedades de economia mista e nas autarquias e na administração direta, enquanto que o Decreto-lei ํo 1.632, de 4/08/78 proibiu a greve nos serviços públicos e em atividades essenciais de interesse da segurança nacional.

A Constituição Federal de 1988, em seguida, passa a tratar do direito de greve assegurando-o aos trabalhadores do setor privado, incluídos os empregados das

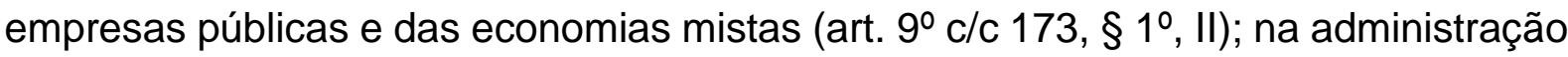
pública direta e indireta (autarquias e fundações públicas), com limites definidos em Lei específica (art. 37, VII), e proibindo ao militar a sindicalização e a greve (art. 142, IV). Complementar a esse dispositivo legal, a Lei oㅡ 7.783, de 28/06/89, dispõe sobre o exercício do direito de greve, definindo as atividades essenciais e regulamentando o atendimento das necessidades inadiáveis da comunidade, sendo portanto o dispositivo legal mais recente sobre o tema.

É possível observar, portanto, uma clara evolução da legislação no sentido de legitimar o movimento de greve e reconhecer sua importância para conquistas trabalhistas e negociação de conflitos entre patrões e empregados.

São assegurados aos grevistas conforme o artigo $1^{\circ}$ da Lei 7.783/89, o direito:

(a) ao emprego de meios pacíficos tendentes a persuadir ou aliciar os trabalhadores a aderirem à greve; (b) a arrecadação de fundos e a livre divulgação do movimento.

Não há dúvida de que os trabalhadores são os titulares do direito de greve, pois compete a eles decidirem sobre a oportunidade e os interesses a serem definidos por meio da greve. Já os sindicatos são responsáveis por tornar legítimo esse direito, já que eles são representantes dos trabalhadores em um direito coletivo. 
Para Martins (2015), a livre divulgação do movimento visa assegurar a comunicação e informação sobre a greve, para que ela possa ser propagada. Há a possibilidade da divulgação por meio de panfletos, de cartazes de propaganda, desde que não sejam ofensivos à pessoa do empregador, assim como o uso de megafone ou veículo com sonorização na porta da fábrica.

No artigo $5^{\circ}$ da Constituição, nos direitos e garantias fundamentais, os grevistas terão o dever de observar no exercício da greve, por exemplo: o direito à vida, à liberdade, à segurança e à propriedade; o respeito às convicções políticas, filosóficas e crenças religiosas; o direito de liberdade de trabalho, de livre manifestação do pensamento, entre outros. Esses direitos são sagrados e os envolvidos não poderão violar esses, além disso, nem ameaçar e causar danos à propriedade ou pessoa, muito menos persuadir os trabalhadores que continuarem suas atividades normais.

O empregador regulará os salários e as demais obrigações trabalhistas durante a greve, por acordo sindical. O mesmo será informado sobre a futura paralização da empresa. Diante disso, o empregador poderá contratar diretamente os serviços enquanto durar a greve para realização de serviços desse fim (Lei 7.783/89, Art. 3o).

Ademais, não será permitido ao empregador adotar meios para constranger o empregado a retornar suas atividades, nem tampouco frustrar ao movimento grevista. Com isso, o empregador não poderá buscar qualquer meio que venha a obrigar, a coagir ao grevista prestar serviços durante a greve e nem impedir sua ampla divulgação.

Diante do exposto, fica notório que o direito de greve é exercido de modo democrático e amplo, contudo também se encontra regulamentado de modo a coibir determinados abusos, seja por parte dos trabalhadores ou dos empregadores. 


\section{ABUSO DO DIREITO DE GREVE}

O abuso surge quando o movimento contempla atos ilícitos e estes afrontam a ordem jurídica. $O \S^{2}{ }^{0}$ do artigo 9ำ da Carta Magna prevê a punição dos grevistas que abusarem do direito de greve.

A lei ํㅡ․ 7.783/89 determina que o direito de greve jamais poderá se sobrepor a direitos e garantias fundamentais, caso contrário será dito como abuso de direito de greve. Caso haja o abuso o grevista responderá nas esferas trabalhista, civil e penal.

Ocorrendo o abuso, este será entendido à luz da Lei ำ 7.783/89, e suas sanções proporcionais ao nível do abuso cometido. Como exemplos do abuso do direito de greve é possível citar:

1. o descumprimento do aviso prévio da paralisação;

2. a deflagração de greve sem assembleia geral;

3. a ocupação ameaçadora de estabelecimentos;

4. a realização de piquetes violentos;

5. sabotagem nas instalações e nas máquinas da empresa

6. agressão física; e

7. boicote aos serviços da empresa.

Diante disto, os atos praticados durante a greve, ilícitos ou crimes cometidos, serão apurados de acordo a esfera pertinente. Os abusos cometidos pelos obreiros poderão sofrer penas aplicadas pelo artigo 482 da CLT, gerando por seguinte dispensa por justa causa.

Outra hipótese proibitiva relacionada à greve é o lockout. O lockout é definido como paralisação realizada pelo empregador, conforme artigo 17 da Lei ํo 7.783/89, com objetivo de exercer pressões sobre trabalhadores, visando frustrar e dificultar a negociação coletiva e o atendimento das reivindicações trabalhistas.

A Lei proíbe expressamente o lockout, pois não é uma hipótese de suspensão do contrato de trabalho pelo empregador, tanto que o mesmo vem sendo considerado na 
jurisprudência como uma interrupção do contrato de trabalho, podendo inclusive dar causa à rescisão indireta do contrato de trabalho se o empregador não proporcionar serviços ao empregado. Além disso, o empregador arcará com todos os direitos dos trabalhadores, caso continue com a paralisação.

O lockout é um movimento provisório, sendo caracterizado como um ato voluntário do empregador. Contudo, não se classifica como greve, pois a greve mostra uma liberalidade (trabalhar ou não), e o lockout veda essa possibilidade aos trabalhadores, além de se caracterizar como manifestação do poder econômico.

Não interpretado como direito, e sim como manifestação de força e poder econômico, trata-se de uma ofensa ao trabalhador para defesa da empresa. Nesses casos, a Lei prevê sanções ao empregador na forma de indenizações pecuniárias (Lei 7783/89, Art. 17).

\section{GREVE NO SERVIÇO PÚBLICO}

O direito de greve do servidor público é assegurado em Lei específica, contida no Art. 37, VII, da Constituição Federal de 1988. Vale ressaltar que esse é classificado, portanto, como um direito constitucional do servidor público, associado também ao direito à livre associação sindical.

Nos moldes da Lei o Superior Tribunal Federal (STF) entendeu que, enquanto não for editada a Lei específica, serão aplicadas as disposições da lei 7.783/89 até que venha a regular o exercício do direito de greve no serviço público. Em outras palavras, não se pode negar o direito de greve aos servidores públicos, pois seria destruir o principal aporte das reivindicações dos servidores, assim, minorando o próprio texto constitucional que assegura 0 direito de greve, e negando o direito destes trabalhadores de lutar por melhores condições trabalhistas.

\section{A GREVE COMO MANIFESTAÇÃO SOCIAL}

A existência de greve fundamenta-se no campo das lutas trabalhistas, a princípio, entre dois atores centrais: patrões e empregados. Contudo, Bourdieu (2003) alerta 
para a existência do papel do Estado nesse contexto, ainda como mediador, e mesmo de outros agentes como Escola (por exemplo) na formação de uma cultura de lutas trabalhistas. Com efeito, na prática,

As relações objetivas que descrevemos sob a forma da tríade "patrãoempregado-Estado" assumem formas concretas muito diferentes dependendo do tamanho da empresa, mas também dependendo do ambiente social da vida do trabalho: vê-se ou não o patrão, vê-se ou não a filha ir à missa, vê-se ou não sua maneira de viver, etc. (BOURDIEU, 2003, P.3)

Questões nacionais, locais e culturais também se impõe na dinâmica do movimento trabalhista, no qual a greve se situa. O papel dos sindicatos é igualmente relevante, uma vez que na luta operária esses atores são, em última análise, responsáveis por definir o nível de razoabilidade e legitimidade dos movimentos grevistas (BOURDIEU, 2003).

Silva (2014, p.214) coloca que

A greve gera debates carregados de emoção, sendo certo que, no Brasil, frequentemente a mídia passa uma imagem de que ela é coisa de baderneiros, arruaceiros, vagabundos.

Incontestável é que, em termos de exercício de reivindicação por parte dos trabalhadores a respeito de melhores condições de trabalho, a greve é um dos mecanismos mais efetivos. Bourdieu (2003, p.7) pondera que "no caso dos trabalhadores, a greve é o instrumento principal de luta porque uma das únicas armas de que dispõem é justamente a paralisação do trabalho".

Em se tratando de greve do ponto de vista da luta operária, Viana (2007) reconhece seu poder como forma de enfrentamento na direção da conquista de melhores condições de trabalho, bem como de defesa de classes oprimidas em geral. Porém, em seu trabalho, sugere uma nova forma de greve, segundo ele mais aderente aos novos padrões sociais vigentes: o boicote. Seu contexto se justifica porque 
Do mesmo modo que a opressão, a resistência tem mostrado cores e formas variadas, tal como a argila nas mãos do artista, ou o camaleão que se ajusta a cada novo ambiente. (VIANA, 2007, p.241)

O boicote é o vislumbre da possibilidade de o sindicato se organizar em categorias ampliadas, numa luta contra o sistema como um todo, enfocando em suas principais distorções.

Diante do modo capitalista de trabalho, a tensão entre patrões e empregados tornase até mesmo natural, proveniente da própria dinâmica da exploração de um trabalho que é livre, democrático, mas ao mesmo tempo subordinado. Além do conflito entre as principais classes envolvidas - empresas, trabalhadores, sindicatos - há que se notar também conflitos entre atores de mesma classe (VIANA, 2007). Sua importância é assim incontestável, porque fora do contrato é possível ao trabalhador se ver e ver a outros trabalhadores, comparando-se às demais condições presentes no mercado de trabalho.

\section{CONSIDERAÇÕES FINAIS}

Sintetizando os entendimentos jurídicos sobre o direito de greve no Brasil da atualidade, o mesmo se caracteriza como direito Constitucional garantido ao trabalhador. Assim, durante a greve as empresas não podem intervir na divulgação do movimento, nem adotar meios para forçar aos empregados comparecerem ao trabalho. Ainda respeitando o direito do trabalhador de aderir ou não a esse tipo de movimento, os grevistas não podem impedir o acesso ao trabalho àqueles que o queiram, e deverão observar os direitos e garantias fundamentais de outrem, no período do direito de greve. Já sobre os abusos cometidos pelos obreiros durante a greve, poderão ocorrer desde demissões por justa causa até responsabilidade penal por crime de dano à coisa, de lesão corporal, conforme Código Penal.

O direito de greve reflete coletivamente os valores fundamentais de cada indivíduo, e esses se manifestam na luta contra os abusos cometidos pelos empregadores. Sua importância para as relações trabalhistas é fundamental, como salienta Viana (2007, 
p.254): "embora também sirva de arma contra violações da lei, ela se presta especialmente para fabricar a lei, num contexto em que a lei não se ajusta ao direito ou à justiça".

Para além do sentido estrito, é possível compreender a greve como forma de expressão e de exercício da liberdade, da indignação. O conflito e a luta de classes promovidos pela greve também são, de outro lado, componentes importantes para o aprendizado e acomodação dessas relações (patrão, empregado, sindicatos), já que forçam o diálogo e a discussão das condições de trabalho como item decisivo para a produtividade - e continuidade - das organizações.

\section{REFERÊNCIAS}

ASSOCIAÇÃO BRASILEIRA DE NORMAS E TÉCNICAS (ABNT). Referências bibliográficas: NBr 6023. São Paulo: ABNT, 2006.

BOLDT, G. et. al. Le droit du travail dans la communauté. Louxembourg: Communauté Européen du Charbon et L'Acier. 1961.

BOURDIEU, P. A greve e a ação política. In: Questões de Sociologia (Trad. Miguel Serras Pereira). Lisboa: Fim de Século - Edições, 2003. p. 269.

BRASIL (Constituição 1988). Constituição da República Federativa do Brasil. Diário Oficial [da] República Federativa do Brasil, Brasília, DF, 5 out. 1988.

BRASIL Lei oㅜ 7.783, de 28 de junho de 1989 2. Dispõe sobre o exercício do direito de greve, define as atividades essenciais, regula o atendimento das necessidades inadiáveis da comunidade, e dá outras providências. Diário Oficial [da] República Federativa do Brasil, Brasília, DF, p. 10.561, 29 jun. 1989.

DELGADO, M. G. Curso de direito do trabalho. 8ª ed. São Paulo: LTR, 2009. 
DIEESE. Balanço das greves em 2012. Caderno de Estudos e Pesquias no66. Maio de 2013. Disponível em http://www.dieese.org.br/balancodasgreves/2012/estPesq66 balancogreves2012.pdf. Acesso em 16/01/16

GILLON, E. et al. Petit Larousse, Librairie Larousse, Paris, 1960, p. 493.

HAURIOU, P. 1961, p.160 apud NASCIMENTO, Amauri Mascaro. Curso de direito do trabalho. 19åed. São Paulo: Saraiva, 2004.

MARTINS, S.P. Curso de direito do Trabalho. 7 ed. São Paulo - Atlas, 2015;

MARTINS, G.; THEOPHILO, C. Metodologia da investigação científica para ciências sociais aplicadas. São Paulo: Pearson, 2009.

MARX, K.. O capital: crítica da economia política. Coordenação e revisão de Paul Singer. Tradução de Regis Barbosa e Flávio R. Kothe. São Paulo: Nova Cultural, 1996. (Os Pensadores, livro 1, tomo 2).

NASCIMENTO, A.M. Comentários à lei de greve. São Paulo: LTr 1989;

SILVA, O.P. Greve e ética na Universidade. Estud. av.[online]. 2014, vol.28, n.80, pp. 213-222.

SÜSSEKIND, A. Direito constitucional do trabalho. Rio de Janeiro: Renovar, 1999;

VIANA, M.T. Da greve ao boicote: os vários significados e as novas possibilidades das lutas operárias. Revista da Faculdade de Direito da UFMG. Belo Horizonte, no 50, p. 239-264, jan. - jul., 2007

Enviado: Janeiro, 2019.

Aprovado: Maio, 2019. 